\title{
Competence-based approach: prerequisites and prospects for studying the mechanisms of managing the emotional response of schoolchildren
}

\author{
Natalia Verkhoturova ${ }^{1,2, *}$ \\ ${ }^{1}$ Krasnoyarsk State Pedagogical University named after V.P. Astafyev, 660049, 89, Ada Lebedeva \\ Str., Krasnoyarsk, Russia \\ ${ }^{2}$ International scientific and practical laboratory accompanying children with disabilities, Moscow \\ Region State University, 24, Vera Voloshina Str., 141014, Mytishchi, Russia
}

\begin{abstract}
Emotional processes are the most important class of mental manifestations in human life, the state of which largely determines physical and social well-being, mental and somatic health, as well as the success of the subject in all types of his life. The accumulation and expansion of emotional experience, its development, consolidation and modification under the influence of purposefully organized education and upbringing, as well as the impact of cultural and conventional norms adopted in a particular society, consistently lead to the formation of a significant group of abilities, knowledge and skills that reveal the emotional literacy of an individual in management of emotional response and characterizing the behavior of the subject from the point of view of his rationality, consciousness, criticality, regulation, self-control and selfmanagement. The presence of emotional literacy determines the social maturity of a person, which is revealed in his emotional competence when interacting with the social environment.
\end{abstract}

\section{Introduction}

The variety of the organic and objective world, forms of social cooperation between people do not leave a person indifferent to everything that happens around him. Perceiving the surrounding reality, a person reflects images of objects and phenomena, the basis of which is his subjective attitude towards them. Reflection of information by the subject always has a personal meaning and presupposes an attitude towards what he reflects. The mechanisms of the emergence and expression of subjective relationships in the field of human mental phenomena are revealed by the system of emotional response. The process of reflecting information expresses an individual's assessment of a certain situation related to the quality of satisfaction of the subject's needs. In the very mechanism of reflection, there is an immediate act of assessing the information entering the brain, which is expressed

\footnotetext{
*Corresponding author: verhotyrovs@mail.ru
} 
in various forms of emotional response: from a glimpse unconscious emotional response to emotiogenic stimuli to intense and long-term emotional experiences.

The concept of emotional response as a complex psychophysiological phenomenon was formed in psychology due to a large number of interdisciplinary studies carried out by domestic and foreign authors. In these studies, a close relationship was established between the mental and physiological components of the emotional response, which determine the occurrence and nature of the emotional reflection of information. In scientific approaches and teachings, the improvement of emotional response in childhood correlates with the processes of maturation, cognitive and personal development, the expansion of the field of social contacts and interpersonal interaction with adults and peers.

As the child develops, the forms of emotional response become more complicated and improved, representing a complex of voluntary and involuntary emotional responses to the effects of the external and internal environment. The consistently accumulated by the child personal and social utilitarian experience of their use, as well as the level of development of dispositions, value orientations, intellectual, personal and regulatory constructs are formed into higher forms of emotional behavior, conditioned by complex psychophysiological mechanisms. Such higher forms of emotional response are characterized by the integrity of emotional images, their objectivity, personal meaning, mediation and generalization of experiences, conscious regulation, self-control and voluntary control.

In modern scientific research of domestic and foreign authors (I.N. Andreeva [1-2], N.Yu. Verkhoturova [3-7], P.L. Harris [8], A.D. Kosheleva, V.I. Pereguda, O.A. Shagraeva [9], P. Lafrene [10], L.A. Sroufe [11], A.V. Zaporozhets, Ya.Z. Neverovich [12], V.V. Lebedinsky [13], etc.), forms of emotional response in childhood is considered as a process of progressive development of emotional literacy, ascending from elementary forms of emotional reflection to higher socially determined, consciously regulated and controlled forms of emotional behavior.

The problem of regulation and self-regulation of behavior as a key one in modern psychology was raised in the dissertation research by T.S. Kiseleva [14], according to which the effective interaction of a person in society and in his life largely depends on the ability to regulate his own behavior, cope with life tasks and difficulties, as well as from the internal resources of a person, ensuring the implementation of these abilities. Studying the role of emotional intelligence as an internal individual resource for regulating human life, T.S. Kiseleva [14] obtained empirical data confirming the possibility of an arbitrary increase in the level of emotional intelligence of a person through a targeted teaching influence on the development of its components within the framework of the model of cognitive abilities. The conclusions obtained from the results of the educational impact program developed by the author testify to the effectiveness of the development of individual human resources, which make it possible to overcome difficult life situations and ensure the success of his adaptation in the social environment.

In modern domestic and foreign psychology, the study of the mechanisms of regulation, control and management of emotional response is considered in the context of the problematic field of research on emotional intelligence. The observed growth of scientific interests in this area, as well as publications and defended dissertations that have appeared over the past decade on various aspects of this problem, indicate the high theoretical significance and practical value of psychological knowledge in the area under study $[1,14$, $15,16,17,18]$. The numerous approaches and different theoretical interpretations of emotional intelligence available in psychology testify to its complex multifaceted structure, which is revealed in the integrative complex of socially significant abilities of cognitive and emotional processes and psychophysiological mechanisms that ensure the effectiveness of the performance of activities that are formed during life and affect the success of the socialization of the individual. 
The purpose of the research was to provide an analytical review of theoretical and methodological premises and scientific approaches to the study of socio-psychological mechanisms for managing the emotional response of schoolchildren by means of forming their emotional competence; assessing the current state of the study of the problem and determining the prospects for research in the area under consideration.

The subject of the study was the process of managing the emotional response of schoolchildren through the purposeful formation of their emotionally competent behavior, which is revealed in the skills of regulation, control and management of emotional response in a social environment. It was revealed that the purposeful formation of emotionally competent behavior of schoolchildren is the key to their successful social adaptation and socialization in the conditions of modern society, since it has a significant impact on the development of self-regulation processes of their behavior, as well as the formation of skills in managing emotional response in a social environment. Despite the theoretical and practical significance of these studies, many issues that reveal the conditions, factors, mechanisms and technologies of purposeful management of the emotional response of schoolchildren remain almost unstudied and require further development.

\section{Scientific exposition}

The concept of "emotional intelligence" is closely related to the idea of a person's emotional literacy, i.e. a purposeful increase in his social and emotional competence in the emotional regulation of behavior and the management of emotional response in the surrounding reality. An analysis of recent studies $[2,15,16,17,18]$ suggests that the social adaptation of a personality, its success, flexibility and mobility are largely determined by the quality of the formation of emotional competence, which is revealed in a generalized complex of abilities to regulate and manage emotional response in various types of practical activities and social interaction $[3,5,6,7]$.

In psychology, the traditional understanding of emotions has developed as complex psychophysiological formations that are the result of the systemic activity of the brain, on the one hand, and the product of the cultural and historical development of mankind, on the other. This concept of emotions predetermined the emergence of a significant number of various scientific approaches of domestic and foreign scientists as to understanding the phenomenological essence of emotional response, the nature and mechanisms of its occurrence; the identification of structural and functional characteristics and patterns that determine its formation in ontogenetic development, and stimulated the development of a wide variety of taxonomists, subdividing emotional reactions into different classes and subclasses, and periodization schemes for the development of emotional regulation of behavior in childhood.

The variety of characteristics, functions and components of emotions testifies to the need to understand emotional manifestations as complex systemic formations with a multilevel and multicomponent structure, the organization of which is dynamic in nature, develops in the process of ontogenesis through the maturation of the nervous substrate and the accumulation of sociocultural experience $[4,6,7]$. Socio-psychological analysis of the problem of the formation of emotional response showed that a person's emotional experience changes and enriches as his cognitive, personal, psychophysical and psychosocial development, the improvement of regulatory mechanisms, as well as the expansion of the field of social interaction with the surrounding reality.

Let us analyze the concept of "emotional regulation of behavior" presented in both domestic and foreign literature. Understanding the structural composition and functional content of this concept, its component content and essential characteristics will be of great importance in the study of psychophysiological mechanisms for controlling the emotional 
response of schoolchildren and their consistent cumulative formation in the process of individual life; will help determine the scientific and methodological prerequisites, assess the deficiencies and research prospects in the area under consideration.

With all the differences in views, the concept of "emotional regulation of behavior" is traditionally considered by scientists (I.N. Andreeva [1-2], N.Yu. Verkhotuova [3, 4, 6], P. Lafrene [10], A.V. Zaporozhets, A.D. Kosheleva, Ya.Z. Neverovich [12], R. Thompson [19]) and others) as an integrative complex of cognitive, affective, regulatory processes and properties aimed at the regulation, control and management of emotional manifestations in adaptation of the individual to various situations of the surrounding reality associated with social interaction and objective activity.

Emotional regulation in the studies of R. Thompson [19] is defined as a system of complex multicomponent structures that administer cognitive, regulatory and behavioral processes with a complex hierarchical structure, mediated by biological maturation, social and cultural determinants. In the course of ontogenetic development, these processes undergo progressive changes in their physiological and mental status, become arbitrary and controllable.

The study of progressive changes in the structure of emotional regulation of behavior was carried out by Alan Sroufe [11], who pointed out the direct dependence of the improvement of the mechanisms of regulation and control and management of emotional processes on the state of maturity of physiological, cognitive and behavioral systems, which he considered as complementary parts of emotional development.

Of particular scientific interest is the study of the emotional regulation of behavior by $\mathrm{P}$. Lafrene [10]. Based on the theoretical analysis of the essence of the phenomenon of emotional regulation, reflected in the works of domestic and foreign scientists, P. Lafrene developed a research model and implemented a series of experimental measures to study the hierarchical formation of emotion regulation processes in childhood. The results of the study were conclusions about the features of the ontogenetic complication of qualitative and quantitative characteristics in the processes of understanding, recognition, verbalization and regulation of emotions - defined by the author as parameters for assessing the "expansion of the emotional world" in childhood and the formation of social competence on this basis. The author paid special attention to the development of the mechanisms of regulation of emotions to the processes of purposeful training in the skills of managing emotional response and the processes of socialization.

Of great importance for understanding the essence of socio-psychological mechanisms of the formation of emotional regulation of behavior in the process of individual life is the concept of intergroup adaptation by A.V. Bulgakov [20]. In the presented theoretical model, emotional phenomena in their development and design are considered as one of the components that form the subculture of society. According to the scientist, the phenomenological basis for understanding the objective reality of emotional phenomena and the mechanisms of their formation in the process of individual life should be the projection of two aspects: structural and functional one and value and worldview one. Let us carry out a socio-psychological analysis of the formation of mechanisms for managing emotional response in childhood in the projection of the indicated aspects.

In the context of the development of the teachings of A.V. Bulgakov [20], the structural and functional aspect of the analysis allows studying the processes of formation, accumulation and complication of the emotional response system as a multicomponent, multifunctional, multilevel structural and hierarchical formation. The multidimensional and multicomponent structure of emotional response, although it is a complex object of research, but at the same time, being subjected to the analysis of its structural and functional content, can be both holistically studied and substantively concretized, taking into account the stage dynamics of age-related changes for each element of its component 
organization, including the sequential accumulation of neoplasms in cognitive, affective and regulatory mechanisms. Structural and functional analysis of the obligatory components of the system allows tracing the sequential formation of such essential characteristics of emotional response as the mediated structure and arbitrariness of the ways of functioning.

Study of the processes of formation of socio-psychological mechanisms for managing emotional response from the standpoint of analyzing their value and worldview component, in the context of the theoretical model of intergroup adaptation by A.V. Bulgakov [20], makes it possible to trace the individual path of the formation of complex culturally determined forms of emotional response, the formation of which occurs in the active appropriation by the subject of social values, cultural norms, traditions and existing rules of behavior in a particular society.

Based on such a complex multifaceted socio-psychological analysis of the content and mechanisms of the formation of emotional regulation of behavior in childhood (in the context of the study of the phenomenological foundations of its structural-functional and value-worldview determinants), it seems possible both a holistic integrative study of emotional response in the unity of its structural components, and the study of the processes of its progressive development through a differentiated analysis of the dynamics of accumulation and complication of the main qualitative new formations of emotional literacy in each of the obligatory components of its structural organization.

The study of the processes of sociocultural determination of emotions and their sign mediation opens up prospects for a comprehensive multifaceted study of individual and social patterns that affect the formation of psychological mechanisms and strategies for emotional regulation of behavior in childhood. Transforming human activity in the direction of achieving the goals set, control and regulation of experienced emotional states; generalization and accumulation of emotional images and their use in new conditions; reflection and change in one's own behavior in accordance with the circumstances and social conditions are determined by the formation of emotionally competent behavior and can be considered as a predictor of a person's success in all spheres of life.

\section{Discussion}

The theoretical and methodological foundation of the model developed by us for studying the socio-psychological mechanisms of managing emotional response was based on the fundamental teachings of the cultural-historical and activity approaches (L.S. Vygotsky [21-23], G.M. Breslav [24], B.V. Zeigarnik [25], A.N. Leontiev [26], S.L. Rubinshtein [27], D.B. Elkonin [28] and others). The quintessence of the existing theoretical views were the provisions that can be considered as technological tools for the formation of emotionally competent behavior of schoolchildren, which is revealed in the skills of regulation, control and management of emotional responses in a social environment. Let's consider them in more detail.

1. Sign mediation of higher mental functions as a psychological mechanism for their regulation, control and management. The fundamental connection between the regulation process and the mediation of behavior was first identified by L.S. Vygotsky [22]. According to the scientist, one of the main essential characteristics of higher mental functions is their mediation by a qualitatively different form of the subject's activity, which is caused by a complex set of reactions. This type of transformative activity presupposes the presence of a system of mediation in the interaction of a person and the environment, which, in turn, radically changes the structure and nature of mental functions and behavior. The scientist calls stimuli-means created by a person to control his behavior "signs", defining them as "tools" for mental development: "a sign is a means for psychological 
influence on one's own or someone else's behavior, a means of internal activity aimed at mastering the person himself' [22, p. 78]. The shift of the vector of the direction of the sign inward - to transform oneself and one's mental activity, qualitatively changes the organization of all mental activity of the subject and mediates the formation of arbitrary forms of mental regulation, control and management of behavior.

2. The system of social meanings assimilated by a person represents the basis of consciousness. The concept of a sign as a stimulus-means artificially created by a person in the process of cultural and historical development, helping him to master his behavior, was originally presented in the teachings of L.S. Vygotsky [22], and then was reflected in the works of B.V. Zeigarnik [25], A.N. Leontiev [26], S.L. Rubinshtein [27], D.B. Elkonin [28], L.I. Bozhovich [29] and other scientists. In the process of individual development of a person and his socialization, there is a consistent appropriation of a system of signs and their meanings artificially created in society. Acting as a guide between the subject and the surrounding reality, the sign is saturated with meaning and represents a personal meaning for the subject, helping him to master his behavior.

Thus, in the process of individual development of personality, emotions, along with other mental functions, lose their "natural" character and become controlled, regulated and managed by the person himself. The mediation of emotions consistently becomes more complex in connection with the development of cognitive processes, which, in turn, leads to a further complication of the forms of emotional response and the improvement of the processes of voluntary regulation, control and self-management. The process of interiorization of signs and their meanings goes from external management to comanagement and ends with the stage of self-government. Cultivating social experience and, together with it, mastering the system of meanings, a person consistently builds up an internal picture of personal and semantic formations, which leads to a complication of the essential characteristics of emotions, an improvement, and a variety of forms and mechanisms of emotional regulation and control of his behavior.

According to B.V. Zeigarnik [25], the search and use of "auxiliary" means, as a system of social meanings assimilated by a person, conceal a regulatory function. At the level of "auxiliary action", the process of mediation is of a regulatory nature. The system of signs and their meanings help a person to master his behavior and direct him in accordance with the goals identified as priorities. According to the theoretical views of the scientist, one can speak about the mediation of behavior only when a person is not only aware of the situation and his possibilities in it, but also when he can independently obtain the appropriate knowledge, determine on this basis his experiences and feelings generated by the object of his consciousness. In this case, mediation acquires an "auxiliary" character: it serves another activity - the emotional regulation of behavior.

3. The objective nature of emotions ensures their accessibility for voluntary regulation. This position is revealed in the teachings of many Russian psychologists (G.M. Breslav [24], A.N. Leontiev [26], S.L. Rubinshtein [27], A. Sh. Tkhostov, I.G. Kolymba [30], V.K. Vilyunas [31]). In the works of the authors, the role of the subject content of emotions is indicated, acting, on the one hand, as a response to the subject of need, and on the other, as a necessary condition for their awareness. Each new subject area with which a person comes into contact in social practice is reflected in his consciousness, generates new feelings and emotions, in which new relations of the subject with the world are established. The relationship of active transformation of the world leaves a significant imprint on the development of the entire emotional sphere, determine and direct transformative activity, which has not only external, but also internal content.

The variety of emotional images and the maturity of the emotional sphere directly depend on the experience of a person's life relationships in various situations, as well as on the types of practical activities through which they are carried out. The transforming 
activity of a person contributes to the accumulation of emotional images and generalizations, changes and improvement of the qualitative characteristics of emotions, stimulates cognitive activity, the development of the motivational-need sphere and the whole personality; predetermines the formation of mechanisms of regulation, control and management of behavior.

A necessary condition for the subject's conscious and independently controlled emotions is the ability to correlate emotional reactions with the context of the situation, as well as with the nature of the subject's activity and the vector of interaction with the outside world. One of the indicators of the availability of voluntary regulation of emotions is the ability of a person to understand the sign-objective content of emotional reactions and to generalize the practice of emotional experiences into images, cumulatively accumulating and improving his personal emotional experience. It follows from the formulated statement that the ability to assess and reflect on one's emotional state, as well as the ability to trace the connection with the objective essence of emotion, is a condition and source for the development of arbitrary forms of emotional response management.

4. Mediated personality behavior is the source of the emergence of new motives and a condition for the formation of reflexive, controlled and voluntary behavior. The process of the formation of the emotional sphere is inseparable from the entire process of the formation of personality and mental activity. The unity of cognitive, affective and behavioral aspects of mental development was recognized by many Russian psychologists. Scientific provisions on the "semantic structure of consciousness", "semantic structures", "semantic field", "personal sense" at the conceptual level were presented in the works of L.S. Vygotsky [21-23], B.V. Zeigarnik [25], A.N. Leontiev [26], D.B. Elkonin [28].

Starting with the teachings of L.S. Vygotsky, emotions began to be considered as a systemic formation in the unity of affective, cognitive and personal components of mental activity, and the possibility of conscious regulation was explained by structural mediated interrelations of these aspects as complex semantic formations of the personality.

A.N. Leontiev [26] held a similar point of view, pointing out the existence of two systems of human connections with the surrounding reality: cognitive and semantic. The scientist notes that in human life, these systems are fused together and form an integral semantic system. As a result of a person's mental activity, semantic formations are included in the transforming activity of the subject and thereby begin to exercise the function of regulation and control over the entire process of life. In turn, the change in human activity, his behavior is mediated by the improvement of the cognitive, personal, emotional spheres of mental development; a change and awareness of meaning-forming motives, a change in a person's attitude to the world, to himself, to people around him. Improving the processes of mediating behavior is associated with the formation of structural links of self-awareness, self-esteem of the individual, as well as the development of the ability to reflect on one's behavior.

5. Experience as a systemic dynamic unit of consciousness. Solving the problem of finding an integral "indecomposable unit of intelligence and affect", L.S. Vygotsky [22-23] expressed a peculiar view of personality, which consists in understanding it as a psychological category, primary in relation to activity and consciousness. Developing this point of view, the scientist introduces the category of "experience" into the scientific apparatus of psychology, focusing on its special status: "Experiencing is a unit of consciousness, i.e. such a unit where the basic properties of consciousness are given..." [22, p. 382]. The aggregate representation of affective and cognitive, regulatory and motivational complexes in their integrative relationship and interdependence mediates the progressive emergence in the structure of emotional response of new qualitative characteristics of a higher order, which are revealed in the possibilities of conscious regulation and control of emotional behavior. 
L.S. Vygotsky [22-23] develops the idea that not only the higher mental functions themselves, not only consciousness has social and cultural determination, but the main thing is the social origin and social nature of the personality itself, which subordinates both consciousness and individual mental cognitive, emotional, motivational processes, including regulatory mechanisms of behavior control. Any experience as a mental phenomenon and the ability to control it are determined by personal development, reflect the level and nature of personal maturity, and are necessarily included in the sphere of human emotionality and regulation of behavior.

The positions we have considered characterize the complexity of the process of the formation of emotional response in childhood and its mediation by a wide variety of factors and mechanisms that determine the formation of higher forms of emotional regulation of behavior and the formation of mechanisms of voluntary control.

\section{Research results}

Analysis of the current state of the problem and the presented scientific and methodological provisions allow considering emotional response as a dynamic functional system formed by a complex integrative complex of mutually conditioning processes, properties and psychophysiological mechanisms, which are based on a multi-level and hierarchical organization that develops in the process of individual human life through social interaction, appropriation of cultural experience, as well as purposefully organized learning and education processes.

The understanding of emotional response as a complex life-developing system is built on the foundation of theoretical and methodological ideas and provisions of A.V. Zaporozhets [12], L.S. Vygotsky [22-23], B.V. Zeigarnik [25], A.N. Leontiev [26], S.L. Rubinshtein [27], D.B. Elkonin [28] and others. The doctrines under consideration emphasize the determining role of social mediation in the formation of psychological mechanisms of emotional regulation of behavior, which characterize the behavior of the subject from the point of view of his rationality, consciousness, criticality, controllability and controllability, serving as an indicator of general mental, emotional and personal maturity. In line with these theoretical and methodological provisions, the decisive importance in the development of the ability to manage the emotional response of schoolchildren is assigned to the processes of learning, the result of which is the formation of the emotional literacy of the pupil.

The presence of a hierarchical dynamics of progressive changes in the development of higher forms of emotional response can be considered as a consistent "build-up" of emotional experience, which is revealed in the emotional literacy of the pupil, his knowledge, skills, abilities to adequately understand the emotional reactions of others, constructively express his own emotions, productively emotionally interact based on external expressive means of emotional response, to exercise emotional regulation, control and management of their behavior in situations of social interaction, while maintaining their emotional well-being and health. The presence of emotional literacy, in turn, guarantees certain personality traits that are revealed in emotional competence, which have a significant impact on the emotional well-being of the individual, the development of selfregulation processes of behavior, and the formation of skills for managing the emotional response of schoolchildren in a social environment.

In the context of the competence-oriented ideology of modern education, aimed at the development of a culturally competent person with the necessary set of socially significant personal competencies, it is of particular importance to study the mechanisms of managing the emotional response of schoolchildren in order to form emotionally competent behavior 
in them, which is revealed in the skills of regulation, control and management of emotional responses in situations of social interaction.

The unquenchable interest of psychologists and the wide public demand for practical knowledge on emotional response management stimulated researchers to study emotional intelligence as an integrative complex of socially significant abilities that are revealed in the unity of cognitive, affective and regulatory competencies, the cumulative design of which determines the emotional literacy of an individual and characterizes the behavior of a subject with the point of view of his consciousness, criticality, regulation, self-control and self-management. This trend has determined an active search for scientific and methodological approaches and substantiations of psychophysiological mechanisms of the formation and design of complex socially determined forms of emotional response in childhood.

The numerous approaches and different theoretical interpretations of emotional intelligence available in psychology testify to its complex multifaceted structure, which is revealed in a complex of socially significant abilities that ensure the effectiveness of the performance of activities that are formed during life and affect the success of the socialization of the individual. In modern studies, it is indicated that in the ontogenetic development of a person, emotional intelligence is not innate, its formation occurs in the process of individual life and is determined by social factors, which makes it possible to exert a formative influence on it at different age periods.

The need for a purposeful formation of the personality's abilities to manage their emotional response was indicated by many domestic and foreign scientists, defining different conditions, means and mechanisms for this. The analyzed works allow considering emotional competence as a group of abilities for self-regulation and regulation of emotional response, which are revealed in interpersonal relationships by understanding their own emotions and the emotions of others, as well as a high emotional insight of a person. The mature emotionality of the individual and the ability to manage his emotional response contribute to a more effective orientation of a person in the world and adaptation in society.

The study carried out a socio-psychological analysis of the formation of mechanisms for managing the emotional response of schoolchildren in the context of the concept of intergroup adaptation by A.V. Bulgakov [20], which allowed studying the development and formation of the processes of regulation, control and management in the projections of the structural-functional and value-worldview aspects. In the developed research model, an attempt is made to present the integrity of emotional response as a multidimensional and multicomponent education, the structural organization of which contains a complex of obligatory components that make it possible to assess the emotional literacy of schoolchildren both in their integrative unity and differentially for each element of its component organization, as well as objectively determine the forecast in the development of emotional competence of schoolchildren.

Analysis of the formation of higher forms of emotional response, characterized by the sequential formation of the skills of regulation, control and management in the projection of its structural-functional and value-worldview determinants, showed the structural and hierarchical complexity and versatility of the formation of the processes of emotionally competent behavior; the mediation of their formation by a wide variety of factors and mechanisms.

The integrative relationship and interdependence of affective and cognitive, regulatory and motivational complexes in their cumulative unity of design at each age stage mediates the progressive emergence of qualitative new formations and essential characteristics of emotional competence of a higher level of complexity. The processes, forms and mechanisms of emotional response reflect the staged dynamics of the general mental development of the child and, as a result of ontogenetic development, become more 
complex and meaningful. Analysis of the formation of emotional response in the projections of its systemic and structural and functional organization allows tracing the cumulative integrity of affective-cognitive, regulatory and motivational complexes and indicates the involvement of "system dynamics" of mediations of different levels in the structural and hierarchical process of their formation.

\section{Conclusions}

In the context of the competence-oriented ideology of modern education, aimed at the development of a culturally competent person with the necessary set of socially significant personal competencies, the search and systematics of psychological mechanisms of emotional regulation of behavior, determination of methods for monitoring, assessing and predicting the emotional maturity of a person, and also the development of priority comprehensive programs and technologies for the purposeful increase in emotional literacy and the formation of competencies for managing emotional response is of particular importance.

Analysis of theoretical approaches to understanding the essence of emotional competence allows saying that the majority of researchers consider various aspects of a person's emotional literacy and emotional maturity as the "semantic core" of this concept. The presence of emotional maturity, in turn, guarantees the formation of certain integrative personality qualities (competencies) and the corresponding level of its adaptation to the social environment. There is no doubt that the social adaptation of schoolchildren, their flexibility and mobility in the modern world will largely be determined by the quality of their emotional competencies in managing emotional response.

The results of the analysis of the considered theoretical and methodological approaches and teachings give sufficient grounds to believe that the development of complex forms of emotional response of a person as a socio-historical being cannot be determined by the ratio of separately acting factors and mechanisms, they are caused by their complex combination and cumulative impact in the process of individual life. The variety of models and methods of emotional response, its mechanisms and strategies for expressive expression is mediated by the variety of real life relationships of the individual with the outside world, which are expressed in them, as well as the forms and types of transformative activity through which they are carried out. It follows from the foregoing that the formation of mechanisms for managing emotional responses is mediated by the processes of the subject's interiorization of social meanings, cultural norms and rules of behavior in a social environment. In the future, the accumulated emotional experience will determine the resources of the individual when interacting with the social environment, the choice of the repertoire of models and mechanisms of emotional regulation of behavior, and also reveal the prospect of the possibilities of creative use of the acquired emotional competences in individual practice.

The scientific provisions presented in the paper are, on the one hand, the theoretical and methodological foundation of the research being carried out, which characterizes the hierarchical complexity of the processes of the formation of emotional response in childhood; its mediation by a wide variety of factors and mechanisms that determine the formation of higher forms of emotional regulation of behavior, which we define as the prerequisites for the research being carried out, and on the other hand, are considered as technological tools for the formation of emotionally competent behavior of schoolchildren, which are revealed in understanding the prospects for research. 


\section{References}

1. I.N. Andreeva, Emotional intelligence as a phenomenon of modern psychology (PSU, 2011)

2. I.N. Andreeva, The structure and typology of emotional intelligence: abstract of thesis. to apply for an account. step. doctor of psychol. sciences (Minsk, 2017)

3. N.Yu. Verkhoturova, Psychocorrectional technology for managing the emotional response of primary schoolchildren with intellectual disabilities: author. dis. ... candid. psychol. sciences (Ekaterinburg, 2010)

4. N.Yu. Verkhoturova, Siberian Pedagogical Journal 5, 150-154 (2012)

5. N.Yu. Verkhoturova, Bulletin of Cherepovets State University 4(43).2, 142-146 (2012)

6. A.A. Dmitriev, N.Yu. Verkhoturova, RUDN Journal of Psychology and Pedagodics 1, 124-129 (2013)

7. A.A. Dmitriev, N.Yu. Verkhoturova, Siberian pedagogical journal: scientific and practical edition 3, 90-96 (2018)

8. P.L. Harris, Children and emotion. The Development of Psychological understanding (Oxford, England, Basil Blackwell, 1989)

9. A.D. Kosheleva, V.I. Pereguda, O.A. Shagraeva et al., Emotional development of preschool children (Moscow, Akademy Publ., 2003)

10. P. Lafrene, Emotional development of children and adolescents (St. Petersburg, praimEVROZNAK, 2004)

11. L.A. Sroufe, Emotional Development: The Organization of Emotional Life in Early Years (Cambridge, England, Cambridge University Press, 1996)

12. A.V. Zaporozhets, Ia.Z. Neverovich, A.D. Kosheleva, Emotional development of a preschooler (Moscow, Prosveshchenie Publ., 1985)

13. V.V. Lebedinsky, Mental development disorders in childhood (Moscow, Akademy Publ., 2003)

14. T.S. Kiseleva, Emotional intelligence as a life resource and its development in adults: abstract of thesis. to apply for an account. step. Cand. psychol. sciences (Moscow, 2014)

15. E.S. Sinelnikova, Emotional intelligence as a factor of interaction in conflict: crosscultural aspect: abstract of thesis. to apply for an account. step. Cand. psychol. sciences (St. Petersburg, 2015)

16. T.V. Manyanina, Emotional intelligence in the structure of the psychological culture of a personality: abstract of dis. to apply for an account. step. Cand. psychol. sciences (Tomsk, 2010)

17. I.N. Meshcheryakova, The development of emotional intelligence of psychology students in the process of studying at a university: abstract of thesis. to apply for an account. step. Cand. psychol. sciences (Kursk, 2011)

18. E.A. Khlevnaya, The role of emotional intelligence in performance (on the example of managers): abstract of thesis. to apply for an account. step. Cand. psychol. sciences (Moscow, 2012)

19. R.A. Thompson, Emotion and self-regulation (Nebraska Symposium on Motivation) (1990) 
20. A.V. Bulgakov, Bulletin of the Russian State University for the Humanities: scientific and practical edition. Series "Psychology. Pedagogy. Education" 10(153), 37-59 (2015)

21. L.S. Vygotsky, Questions of psychology 3, 125-134 (1958)

22. L.S. Vygotsky, The history of the development of higher mental functions. Sobr. Vol. 3 (Moscow, Pedagogy, 1983).

23. L.S. Vygotsky, The doctrine of emotions Collection. Sobr. Vol. 4 (Moscow, Pedagogy, 1984)

24. G.M. Breslav, Bulletin of Moscow University 4, 3-11 (1977)

25. B.V. Zeigarnik, Pathopsychology (Moscow, EKSMO-Press Publishing House, 2000)

26. A.N. Leontiev, Needs, motives and emotions. Psychology of motivation and emotions: a reader (Moscow, CheRo, 2002)

27. S.L. Rubinshtein, Fundamentals of General Psychology (St. Petersburg, Piter Publ., 1999)

28. D.B. Elkonin, Child psychology (Moscow, Academy, 2005)

29. L.I. Bozhovich, Problems of personality formation: Selected psychological works (Moscow, MPSI, Voronezh, NPO MODEK, 2001)

30. A.Sh. Tkhostov, I.G. Kolymba, Vestn. Moscow un-that. Ser. 14. Psychology 2, 3-14 (1999).

31. V.K. Vilyunas, The main problems of the psychological theory of emotions. Psychology of emotions: a reader (Moscow, Bulletin of Moscow University, 1984) 